GRASAS Y ACEITES 72 (3)

July-September 2021, e415

ISSN-L: 0017-3495

https://doi.org/10.3989/gya.0329201

\title{
Cold-pressed cactus pear seed oil: Quality and stability
}

\author{
๑M. de $\mathrm{Wit}^{\mathrm{a}}{ }^{凶}, \oplus \mathrm{V} . \mathrm{K}$. Motsamai ${ }^{\mathrm{a}}$ and $₫ \mathrm{~A}$. Hugo ${ }^{\mathrm{a}}$ \\ aDepartment of Microbial, Biochemical and Food Biotechnology, University of the Free State, P.O. Box 339, Bloemfontein, 9301, South Africa \\ ${ }^{\otimes}$ Corresponding author: dewitm@ufs.ac.za
}

Submitted: 11 March 2020; Accepted: 04 June 2020; Published online: 14 September 2021

SUMMARY: Cold-pressed seed oil from twelve commercially produced cactus pear cultivars was assessed for oil yield, fatty acid composition, physicochemical properties, quality and stability. Large differences in oil content, fatty acid composition and physicochemical properties (IV, PV, RI, tocopherols, ORAC, \% FFA, OSI and induction time) were observed. Oil content ranged between $2.51 \%$ and 5.96\% (Meyers and American Giant). The important fatty acids detected were C16:0, C18:0, C18:1c9 and C18:2c9,12, with C18:2c9,12, the dominating fatty acid, ranging from $58.56-65.73 \%$, followed by $\mathrm{C} 18: 1 \mathrm{c} 9$, ranging between $13.18-16.07 \%$, C16:0, which ranged between $10.97-15.07 \%$ and $\mathrm{C} 18: 0$, which ranged between $2.62-3.18 \%$. Other fatty acids such as $\mathrm{C} 14: 0, \mathrm{C} 16: 1 \mathrm{c} 9, \mathrm{C} 17: 0, \mathrm{C} 17: 1 \mathrm{c} 10$, $\mathrm{C} 20: 0, \mathrm{C} 18: 3 \mathrm{c} 9,12,15$ and $\mathrm{C} 20: 3 \mathrm{c} 8,11,14$ were detected in small amounts. The quality parameters of the oils were strongly influenced by oil content, fatty acid composition and physicochemical properties. Oil content, PV, \% FFA, RI, IV, tocopherols, ORAC and $\rho$-anisidine value were negatively correlated with OSI. C18:0; C18:1c9; C18:2c9,12; MUFA; PUFA; $n-6$ and PUFA/SFA were also negatively correlated with OSI. Among all the cultivars, American Giant was identified as the paramount cultivar with good quality traits (oil content and oxidative stability).

KEYWORDS: Antioxidants; Induction time; Oxidation; Prickly pear; Yield

RESUMEN: Aceite de semilla de nopal prensado en frío: calidad y estabilidad. Se evaluó el rendimiento de aceite, la composición en ácidos grasos, las propiedades fisicoquímicas, la calidad y la estabilidad del aceite de semilla prensadas en frío de doce cultivares de nopal producidos comercialmente. Se observaron grandes diferencias en el contenido de aceite, la composición en ácidos grasos y las propiedades fisicoquímicas (IV, PV, RI, tocoferoles, ORAC, \% FFA, OSI y tiempo de inducción). El contenido de aceite varió entre 2,515,96\% (Meyers y American Giant). Los ácidos grasos mayoritarios fueron C16:0, C18:0, C18:1c9 y C18:2c9,12, siendo el C18:2c9,12 el mayoritario con porcentajes entre 58,56-65,73, seguido de C18:c9 que varía entre 13,18-16,07\%, C16:0, 10,97-15.07\% y C18:0 entre 2,62-3,18\%. Otros ácidos grasos, tales como C14:0, C16:1c9, C17:1c10, C20:0, C18:3c9,12,15 y C20:3c8,11,14 se detectaron en pequeñas cantidades. Los parámetros de calidad de los aceites estuvieron estrechamente influenciados por el contenido total de aceite, la composición de ácidos grasos y las propiedades fisicoquímicas. El contenido de aceite, PV, \% FFA, RI, IV, tocoferoles, ORAC y el valor de $\rho$-anisidina se correlacionaron negativamente con OSI. C18:0; C18:1c9; C18: 2c9,12; MUFA; PUFA; n-6 y PUFA / SFA también se correlacionaron negativamente con OSI. Entre todos los cultivares, American Giant fue identificado como el cultivar primordial con rasgos de buena calidad (contenido de aceite y estabilidad oxidativa).

PALABRAS CLAVE: Antioxidantes; Higo chumbo; Oxidación; Rendimiento; Tiempo de inducción

Citation/Cómo citar este artículo: Wit M de, Motsamai VK, Hugo A. 2021. Cold-pressed cactus pear seed oil: Quality and stability. Grasas Aceites 72 (3), e415. https://doi.org/10.3989/gya.0329201

Copyright: (C2021 CSIC. This is an open-access article distributed under the terms of the Creative Commons Attribution 4.0 International (CC BY 4.0) License. 


\section{INTRODUCTION}

Edible cold-pressed oils are functional products because of their bioactive substances such as polyunsaturated fatty acids, tocopherols, sterols, phenols, carotenoids and chlorophyll. These oils have specific characteristics which provide additional health benefits (Boskou, 2017). The use of non-traditional cold-pressed oils to be introduced into the cosmetic and nutraceutical markets is expected to increase. Recently, research on oils from fig seeds from Morocco (Hssaini et al., 2020), lentisk and skeels from Algeria (Brahmi et al., 2020) as well as milk thistle oil and their functional properties were reported. Cactus pear seed oil has been viewed as an important vegetable oil because of its related quality composition factors, namely high concentrations of important fatty acids, for example, linoleic acid $(\mathrm{C} 18: 2 \mathrm{c} 9,12)(\mathrm{C} 18: 2 \mathrm{n}-6)$; vitamin E $(100 \mathrm{mg} / 100 \mathrm{~g})$ and sterols $(1 \mathrm{~g} / 100 \mathrm{~g})$ (Ennouri et al., 2005). In the past, oil quality was estimated based on oil yield and fatty acid composition alone. Lately, in addition to fatty acid composition, the natural antioxidants, tocopherols and sterols are additional important components which define oil quality (Fernández-Martínez et al., 2004). Oil quality has been transformed by the development of oil with enhanced nutritional and functional properties, and these modifications are incorporated when breeding for increased quantities of $\mathrm{C} 18: 2 \mathrm{c} 9,12$.

Cold-pressed cactus pear seed oil is characterized by a high content of unsaturated fatty acids (Sawaya and Khan, 1982). Past research has demonstrated that vegetable oil with the highest unsaturation level is most likely to undergo autoxidation. Martínez et al. (2011) reported that there are elements that can potentially affect the stability and quality of oil in a negative way, for example light, heat, metals, free fatty acids, tocopherols, phospholipids and waxes which contain pro or antioxidant properties. Hydrolytic reactions which are catalyzed by lipases and react with atmospheric oxygen (autoxidation) are a major cause of nutritional and oil quality losses. Naz et al. (2004) explained oxidation as an autocatalytic series of reactions that requires low activation energy. These authors also reported that fatty acid composition and the presence of antioxidants in vegetable oil influences oxidation. Lajara et al. (1990) and Izquierdo et al. (2009) reported that oils containing high contents of oleic acid (C18:1c9) will possibly have greater stability against oxidation and are favored for improved shelf-life. Naz et al. (2004) further reported that to minimize the effect of hydrolytic reactions, cold storage and proper packaging must be applied. Martínez et al. (2011) stated that the oxidative stability of cold-pressed oils is usually measured by the level of peroxide and $\rho$-anisidine values. The level of unsaturation (polyunsaturated fatty acids) (PUFA), especially the level of $\alpha$-linoleic acid $(\mathrm{C} 18: 2 \mathrm{c} 9,12)$ and the amounts of antioxidants may perhaps limit the stability of these oils. Tocopherols are reported to be strong antioxidants which can scavenge peroxyl radicals. Choe and Min (2006) indicated that the stability of these oils is commonly set for 6 months or a year. Normand et al. (2006) stated that oils with high tocopherol contents have greater stability. Cold-pressed cactus pear seed oil was reported to have higher contents $(94.6 \mathrm{mg} / 100 \mathrm{~g})$ of tocopherols than olive oil $(22 \mathrm{mg} / 100 \mathrm{~g})$, soybean oil $(49 \mathrm{mg} / 100 \mathrm{~g})$ and sunflower oil $(49 \mathrm{mg} / 100 \mathrm{~g})$, and close to those of argan oil $(85 \mathrm{mg} / 100 \mathrm{~g})$ (Zine et al., 2013).

Cactus pear seed oil is a promising source of polyunsaturated fatty acids (PUFA), with significant levels of carotenoids and $\gamma$-tocopherols which can be used as antioxidants to preserve lipid components and serve as functional ingredients (Loizzo et al., 2019). Proper utilization of this seed by-product can generate up to $1220 €$ income per ton and is therefore a potentially new economic source (Ciriminna et al., 2017). According to Regalado-Rentería et al. (2018) prickly pear seed oils are rich in functional metabolites and linoleic fatty acids. Furthermore, this oil could be used in foods as a nutritional supplement, as well as an ingredient in cosmetics and pharmaceuticals. A major advantage is that the residual oilcake can be directly used in animal feed or other secondary products.

Recent research on the oil quality of seed oil from different colored cactus pear fruit seed oil found that cultivar played a major role in the composition of the oils (Regalado-Rentería et al., 2018). Furthermore, oil content and the composition of oils from different origins were reported to indicate differences between cultivars from Sicily and those from Algeria and Morocco; while similarities occurred between cultivars from Sicily and Tunisia, indicating an origin/environment effect (Ghazi et al., 2013; Ciriminna et al., 2017; Regalado-Rentería et al., 
2018; Loizzo et al., 2019). In addition, the effect of different species, e.g. Opuntia dillenii, on oil quality was reported. New studies on O. ficus-indica seed oils from countries such as Greece (Karabagias et al., 2020) and Saudi Arabia (Koshak et al., 2020) have been undertaken very recently.

In a previous study done by de Wit et al. (2017), the quality aspects of chemically extracted (Soxhlet extraction) seed oils from a few selected cultivars were quantitatively analyzed. The current study focused on the oil yield, composition, quality and stability of cold-pressed seed oil of commercially produced Opuntia ficus-indica cultivars. O. robusta seed was included as a reference and for comparison purposes. The aim of this study was to determine the quality and oxidative stability of cold-pressed cactus pear seed oil from 12 chosen cultivars. The quality attributes assessed included oil content, fatty acid composition, refractive index, tocopherols, oxygen radical antioxidant capacity, peroxide value and $\rho$-anisidine value; while stability tests included the oxidative stability index (OSI), as well as induction time extrapolated at 25 and $30{ }^{\circ} \mathrm{C}$.

\section{MATERIALS AND METHODS}

\subsection{Seed material used}

Fruit from selected cultivars growing at an experimental orchard outside Bloemfontein (29.0852 $\left.{ }^{\circ} \mathrm{S}, 26.1596{ }^{\circ} \mathrm{E}\right)$ was collected during the 2014 , 2015 and 2016 seasons. Twelve cultivars, namely Algerian, American Giant, Ficus-Indice, Gymno Carpo, Meyers, Morado, Nudosa, Ofer, Tormentosa, Van As and Zastron were chosen. These O. ficusindica cultivars are commercially produced for fresh fruit consumption. The $O$. robusta cultivar, Robusta, represents a different species and was included because it is commonly found and cultivated as animal fodder in South Africa. The fruit collection was done when the fruit reached $50 \%$ color break stage and $\pm 75 \mathrm{~kg}$ of fruit per cultivar were collected to produce $2-3 \mathrm{~kg}$ of seeds. The seeds were extracted with an industrial liquidizer (Ingram Engineering, Zastron, South Africa) which separates the seeds from the pulp and peels. The seeds were washed with water and collected in a rotating sieved drum. The seeds were then dried under direct sunlight for 2-3 days on shade-netting, placed $\pm 1 \mathrm{~m}$ from the ground to allow for sufficient ventilation. The seeds were manually turned regularly. The drying process aimed to dry out any pulp tissue left on the seed surfaces for easy removal and cleaning before pressing. In a previous study done by de Wit et al. (2016), the moisture content in seeds varied from $\sim 3 \%$ to $\sim 7.2 \%$ due to variations in location, season and especially rainfall. The dried seeds were then vacuum-packed and stored in a freezer at $-18^{\circ} \mathrm{C}$ until further analysis.

\subsection{Seed oil extraction (cold-pressing)}

The dried seeds from all cultivars for each season were cold-pressed in a Komet DD85G twin screw plant oil press (Oekotek, IBG Monforts, Germany) at Nattrend/Bauma Investments CC commercial oil pressing laboratory in Montana Park, Pretoria. The oil extracted using the Komet cold-pressing system is subjected to low temperatures and therefore top-quality vegetable oil which can be utilized for human consumption without any further treatment depending on the raw material used (Schramm, 2016; pers. comm.). The oilcake extrudes out of the oil press in the shape of pellets. The oil was then stored in amber screw-cap $50 \mathrm{ml}$ plastic bottles for one week at room temperature before analysis. The oil analysis for each cultivar for each of the three seasons was done in triplicate.

\subsection{Oil yield}

The oil yield from the seeds of each cultivar from each season was determined according to the formula:

Oil yield $(\%)=$ Mass of oil $(\mathrm{g}) /$ Mass of cactus pear seed $(\mathrm{g}) \times 100$

\subsection{Physico-chemical properties}

\subsubsection{Fatty acid composition (fatty acid methyl esters) (FAME)}

Approximately $20 \mathrm{mg}$ of total lipid (from coldpressed oil) were transferred to a Teflon-lined screw-top test tube with a glass pasteur pipette. Fatty acids were methylated to methyl esters by using $0.5 \mathrm{~N}$ sodium hydroxide $(\mathrm{NaOH})$ in methanol and $14 \%$ boron trifluoride in methanol (Park and Goins, 1994). The fatty acid methyl esters (FAME) were quantified using a Varian 430 gas chromatograph with flame ionization detector with a fused silica capillary column (Chrompack CPSIL 88, $100 \mathrm{~m}$ length, $0.25 \mathrm{~mm}$ ID, $0.2 \mathrm{~mm}$ film thickness). Column 
temperature was $40-230{ }^{\circ} \mathrm{C}$ (held 2 minutes; $4{ }^{\circ} \mathrm{C}$ / minute; held 10 minutes). Fatty acid methyl esters in hexane $(1 \mathrm{ml})$ were injected into the column using a Varian CP8400 Auto-sampler with a split ratio of 100:1. The injection port as well as the detector were maintained at $250^{\circ} \mathrm{C}$. The carrier gas was hydrogen, at 45 psi. The makeup gas was nitrogen. Galaxy Star Chromatography Software was used to record the chromatograms. The peaks were identified by comparing the relative retention times of FAME peaks from samples with that of standards from Supelco (Supelco 37 Component Fame Mix 47885-U, SigmaAldrich Aston Manor, Pretoria, South Africa). Fatty acids were expressed as the relative percentage of each individual fatty acid as a percentage of the total of all fatty acids in the sample. The following fatty acid ratios and combinations were calculated from the fatty acid data: total saturated fatty acids (SFA), total mono-unsaturated fatty acids (MUFA), total polyunsaturated fatty acids (PUFA), total omega-6, total omega-3 fatty acid content and the PUFA/SFA $(\mathrm{P} / \mathrm{S})$ ratio.

\subsubsection{Refraction index (RI)}

Refractive Index (RI) was determined according to the Association of Official Analytical Chemists' (AOAC), official method 921.08 (AOAC, 2000) with an Abbè programmed advanced refractometer from ATAGO ${ }^{\circledR}($ Model RX $5000 \alpha)$ at $40{ }^{\circ} \mathrm{C}$.

\subsubsection{Iodine value (IV)}

Hanus iodine Value (IV) was determined by the AOAC official method 920.158 (AOAC, 2000), which consists of adding a mixture of iodine and bromine in glacial acetic acid and measuring the excess of unused halogen by titration with sodium thiosulfate.

\subsubsection{Tocopherols}

High performance liquid chromatography (HPLC) was used to determine the tocopherol amount in each sample using Shimadzu CR8A instruments (Champ sur Marne, France) equipped with a C18Varian column $(25 \mathrm{~cm}$ x $4 \mathrm{~mm}$; Varian Incorporated, Middleburg, Netherlands). One gram of each oil sample was added to $5 \mathrm{~mL}$ of ethanol $(\mathrm{EtOH})$, filtered $(45 \mu \mathrm{m})$ into a HPLC vial at $25^{\circ} \mathrm{C}$. HPLC was carried out with an injection volume of $20 \mu \mathrm{L}$, a flow rate of 1 $\mathrm{ml} / \mathrm{min}$ and estimated at UV of $296 \mathrm{~nm}$. The mobile stages were: mobile stage A (Acetonitrile: Methanol: Isopropanol: Water $(45: 45: 5: 5, \mathrm{v} / \mathrm{v} / \mathrm{v} / \mathrm{v}))$ and mobile stage B (Acetonitrile: Methanol: Isopropanol $(50: 45: 5, \mathrm{v} / \mathrm{v} / \mathrm{v}))$.

\subsubsection{Oxygen Radical Antioxidant Capacity (ORAC)}

For the Oxygen Radical Antioxidant Capacity (ORAC) analysis, the method of Prior et al. (2003) was used, where samples ( $10 \mathrm{~g}$ each) were diluted with $80 \%$ methanol in $\mathrm{H}_{2} \mathrm{O}(1: 1 \mathrm{w} / \mathrm{v})$, and then vortexed for 2 minutes at room temperature and centrifuged for 10 minutes at $500 \mathrm{Xg}$. The peroxyl radicals were generated with 2, 2'-Azobis (2-amidinopropane) dihydrochlorine (AAPH) and B-phycoerythrin (BPE) was used as the detector of radical activity. The final reaction mixture was prepared in 10-mmwide quartz cuvettes as follows: $1600 \mu \mathrm{L}$ of 0.04 $\mu \mathrm{M}$ B-PE in $0.0075 \mathrm{M}$ sodium $(\mathrm{Na})$ - potassium (K) phosphate buffer at $\mathrm{pH} 7.0$ and $200 \mu \mathrm{L}$ of 50 $\mu \mathrm{M}$ Trolox (6-hydroxy-2,5,7,8-tetramethylchroman -2-carboxylic acid). Phosphate buffer was used as a blank $(200 \mu \mathrm{L}$ of methanol, diluted 1:20 (v/v) with $0.075 \mathrm{M} \mathrm{Na}-\mathrm{K}$, at $\mathrm{pH} 7.0$ and Trolox $(\beta$ and $\gamma$ tocopherol analogue) as the standards during each run. Samples were pre-incubated at $37^{\circ} \mathrm{C}$ for $15 \mathrm{~min}$. AAPH was added. Flourescence was measured and measurements were recorded every 5 minutes for 35 minutes at $570 \mathrm{~nm}$ until a steady state (plateau) of fluorescence decay was reached. The results were then calculated and expressed as $\mu \mathrm{mol}$ of Trolox equivalent (TE). The analyses were done in triplicate.

\subsection{Determination of oxidative stability}

\subsubsection{Free Fatty Acids (FFA)}

Free fatty acids were determined according to the method of Pearson (1973), which involves the titration of the oil in an alcoholic medium against potassium hydroxide using phenolphthalein as indicator.

\subsubsection{Peroxide value (PV)}

Peroxide value was determined by the official method of the AOAC 965.33 (AOAC, 2000). Peroxide value determines hydrogen peroxide, a primary oxidation product, and involves peroxides liberating iodine from potassium iodide by calculating the amount of sodium thiosulfate consumed. 


\subsection{3. $\rho$-Anisidine value ( $\rho$-AV)}

The $\rho$-AV was determined using the technique of Hamilton and Hamilton (1992). It determines the amounts of aldehydes and ketones during secondary oxidation by reaction with $\rho$-Anisidine (4-methoxyaniline) using a spectrophotometer at $350 \mathrm{~nm}$.

\subsubsection{Oxidative Stability index (OSI)}

The oxidative stability index (OSI) was determined using the AOAC OSI official method Cd 12b-92 (AOAC, 2000) with a Rancimat 743 apparatus from Metrohm. Three samples were tested per cultivar.

\subsubsection{Extrapolated induction time (Shelf-life prediction at 25 and $30^{\circ} \mathrm{C}$ )}

The oxidative stability index (OSI) was determined using the AOAC OSI official method Cd 12b-92 (AOAC, 2000) with a Rancimat 743 apparatus from Metrohm. Three samples were tested per cultivar. Oxidative stability index (OSI) values were determined at $100,110,120$ and $130{ }^{\circ} \mathrm{C}$ for each sample in duplicate. The extrapolation function of the Rancimat 743 apparatus was used to predict induction times at 25 and $30{ }^{\circ} \mathrm{C}$ (Rancimat Manual, 2009) according to the formula:

Predicted induction time $=\mathrm{A} \mathrm{X} \mathrm{e^{( \textrm {BXT } ) }}$

\subsection{Statistical analysis}

Seed were selected from each of the 2014, 2015 and 2016 harvest. Oil yield was determined for each cultivar for each season. Each measurement was made in triplicate on oil from each cultivar per year. Data were captured for the three years and were reported as average \pm standard deviation using NCSS Statistical Software package, version 11.0.20). The Pearson correlation analysis was done to determine the link between the physico-chemical properties of the oil (NCSS Statistical Software package, version 11.0.20).

\section{RESULTS AND DISCUSSION}

\subsection{Oil yield}

Seed oil content ranged from 2.51 to $5.96 \%$ (Meyers and American Giant), respectively (Figure 1). Gymno Carpo and Morado were amongst those which attained the lowest oil contents (2.72 and $2.78 \%$ ). In a previous limited study, the chemical extraction of seed oils from only seven selected cultivars by de Wit et al. (2017), the oil content ranged from $5.65-8.09 \%$. A subsequent elaborated study on seed oil from 42 cultivars by de Wit et al. (2018) reported oil contents ranging from $4.09-8.76 \%$. The lower yield values reported in the current study were expected since the oil was recovered by pressing and not by chemical extraction as in the above-

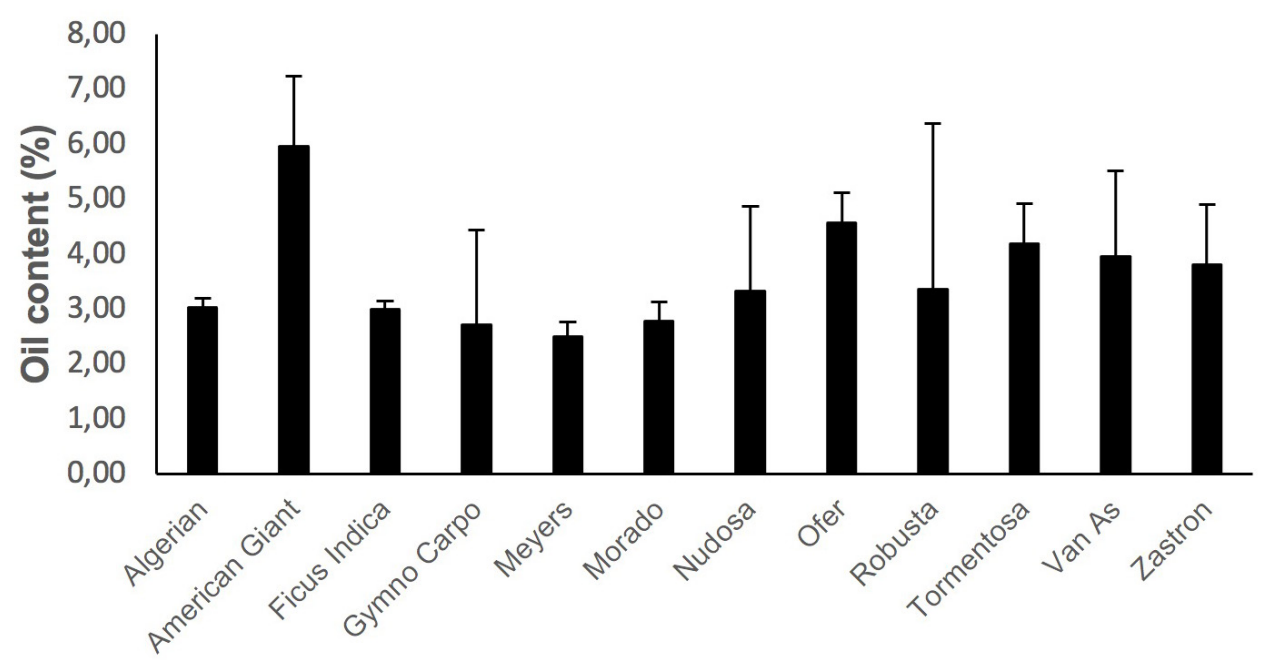

Cultivar

FigURE 1. Oil yield (\%) of cold-pressed oil for all 12 cultivars. Oil yield was expressed as \% Oil yield = Mass of oil (g) / Mass of cactus pear seed (g) x 100. Values in the Figure are mean \pm SD of triplicate analyses. 
mentioned studies. American Giant also obtained the highest oil content in the study of 42 cultivars by de Wit et al. (2018). The values obtained in the current study agree with those reported for the same commercial South African cactus pear cultivars from the Limpopo Province by Labuschagné and Hugo (2010) (2.24 to 5.69\%). That study did not include American Giant.

It was also found by Ortega-Ortega et al. (2017), Ramírez-Moreno et al. (2017), Regalado-Rentería et al. (2018) and Loizzo et al. (2019) that extraction method had an effect on the oil yield of cactus pear seeds. These authors and others, e.g. Ciriminna et al. (2017) also reported the effect of variety and species on the oil yield of cactus pear seeds. High yields of 9.3-9.5 g oil per $100 \mathrm{~g}$ seed were reported for Sicilian cactus pears $(O$. ficus-indica) extracted with hexane by the Soxhlet method, while Ultra-Sound Assisted extraction yielded 5.4-5.6 g/100 g. The highest yields were found in the Turkish and Moroccan varieties $(\approx$ $14 \mathrm{~g} / 100 \mathrm{~g}$ seed) (Chougui et al., 2013). Lower values than those were reported for Algerian (7.3-9.3 g/100 $\mathrm{g}$ seed) and Tunisian fruit seed oils (Chougui et al., 2013). The lowest values were found for the Greek wild $O$. ficus-indica variety (yellow to green fruit) of $5.4 \%$, which was also obtained by cold-pressing (Karabagias et al., 2020). Slightly higher yields were reported for $O$. microdasys (Engelm) $(9.2 \%)$ and $O$. macrorhiza (11.3\%) from Tunisia (Chahdoura et al., 2015). Maceration-Percolation (MP) extraction was used by Regalado-Rentería et al. (2018) to yield oil contents of up to $15.5 \%$ from $O$. robusta species (14.54 - 15.54\%). Oil yields for other prickly pear varieties included $O$. albicarpa $(8.72 \%), O$. magacantha $(6.16-7.63 \%)$, O. matudae $(9.68 \%)$, O. streptacantha $(10.55-11.64 \%)$ and $O$. dillenii (6.5\%) (Ali Asaad et al., 2019).

Fruit color was also indicated as a factor influencing oil yield, e.g. Ramírez-Moreno et al. (2017) reported higher yields from a green cultivar compared to a red cultivar. American Giant from the current study is also a green cultivar. These results support research that pointed out that cultivar, crop, environment and origin (rainfall, soil type and soil nutrients, light, temperature) and extraction method, including extraction solvents (hexane $>$ ethanol $>$ ethyl acetate) influence oil yields. According to Karabagias et al. (2020), the most important factors are variety and extraction process.

\subsection{Physico-chemical properties}

\subsubsection{Fatty acid composition}

The fatty acid compositions of cold-pressed oil from a selection of cactus pear cultivars are shown in Table 1. According to the results presented, there are considerable variations in the fatty acid percentage of the selected cultivars. The dominating fatty acids identified (in decreasing order) were linoleic acid (C18:2 n-6) (C18:2c9,12); oleic acid (C18:1 n-9) (C18:1c9); palmitic acid (C16:0) and stearic acid (C18:0); while palmitoleic acid (C16:1 n-9) (C16:1c9), $\alpha$-linolenic acid (C18:3 n-3) $(\mathrm{C} 18: 3 \mathrm{c} 9,12,15)$, arachidic acid (C20:0) and lignoceric acid (C24:0) were notable in small amounts in all cultivars. C16:0, C18:0, C18:1c9 and $\mathrm{C} 18: 2 \mathrm{c} 9,12$ were the only fatty acids detected at levels of more than $1 \%$. This is in accordance with the results of various authors who reported that cactus pear seed oil contained primarily unsaturated fatty acids namely linoleic and oleic acid, and with a lower but significant content of palmitic and stearic fatty acids (Chougui et al., 2013; Ciriminna et al., 2017; OrtegaOrtega et al., 2017; Ramírez-Moreno et al., 2017, Regalado-Rentería et al., 2018; Loizzo et al., 2019). A completely different profile was found for the Greek O. ficus-indica which included butyric acid (C4:0), palmitic acid, stearic acid and oleic acid as the main fatty acids (Karabagias et al., 2020).

The C18:2c9,12 content varied from 58.56\% (Nudosa) to $65.18 \%$ (Robusta) (Table 1). A slightly larger range for $\mathrm{C} 18: 2 \mathrm{c} 9,12$ between $57.75-67.32 \%$ was reported by de Wit et al. (2017) and de Wit et al. (2018) (56.86-65.21\%). Labuschagné and Hugo (2010) also reported comparable results for fatty acid profiles with unsaturated fatty acids $(\mathrm{C} 18: 2 \mathrm{c} 9,12)$ ranging between $57.75-67.32 \%$. Linoleic acid (omega-6) is an essential fatty acid and a precursor of arachidonic acid (AA) biosynthesis which is the substrate for eicosanoid synthesis (Ghazi et al., 2013). Both present a hypocholesterolemic effect and inhibit colon cancer. Omega-6 PUFA is the source of inflammatory mediators' prostaglandins (PGE) and leukotrienes. Consumption of oleic acid (n-9) and $\alpha$-linolenic acid (n-3) act as AA antagonists and reduces the production of inflammatory mediators (Koshak et al., 2020). Higher levels were found in $O$. microdasys (Engelm) and $O$. macrorhiza as well as $O$. dillenii (> 70\%) (Ghazi et al., 2013; Chahdoura et al., 2015; Ali Alsaad et al., 2019); while the current results 
TABLE 1. Fatty acid composition of oil from 12 selected cold-pressed cactus pear cultivars (fatty acids were expressed as the proportion of each individual fatty acid to the total of all fatty acids present in the sample). Values in the Table are mean \pm SD of triplicate analyses.

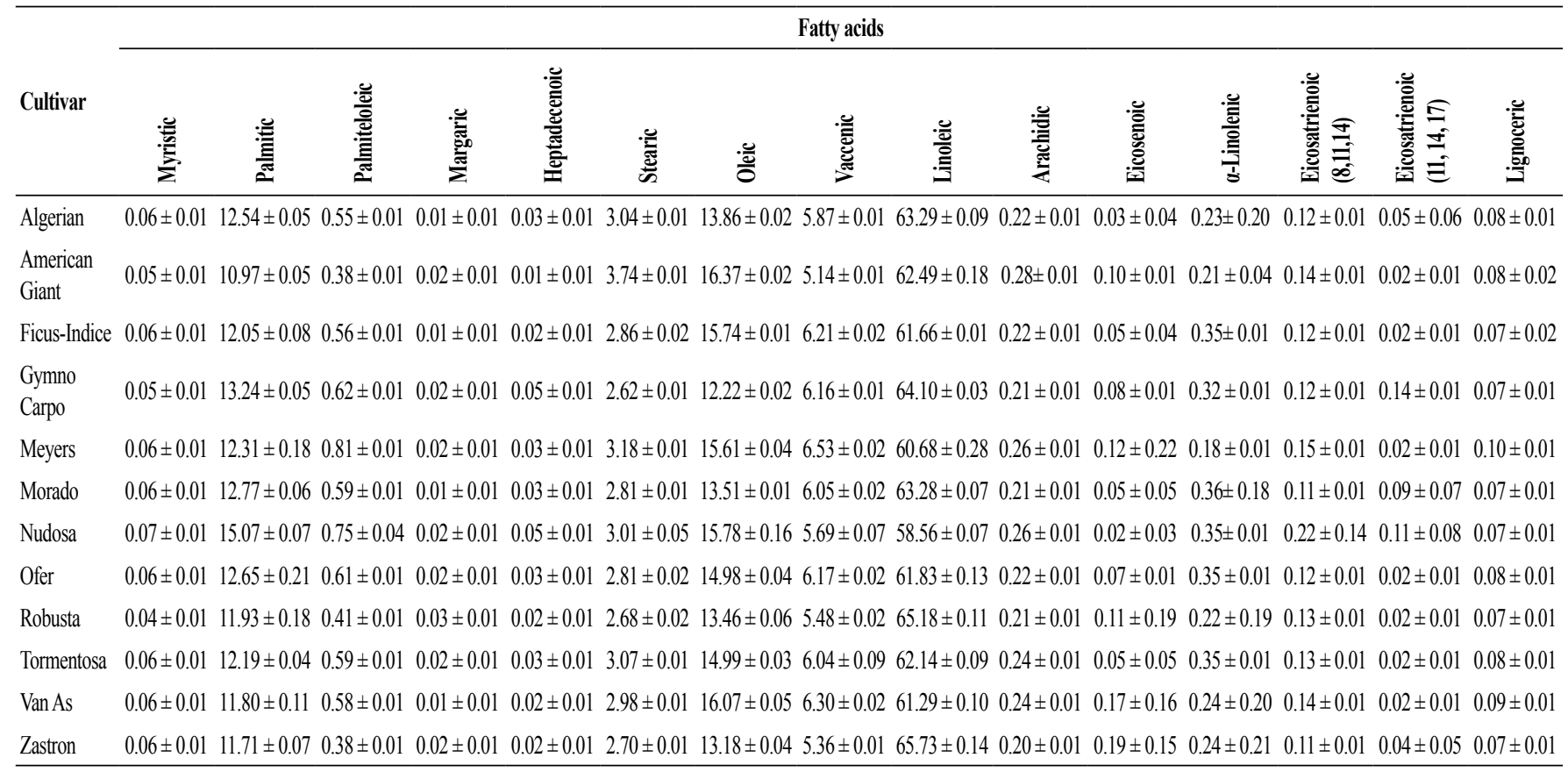

are in agreement with the levels reported for O. ficusindica varieties from Sicily, Saudi Arabia, Turkey and Tunisia (Ghazi et al., 2013; Ciriminna et al., 2017; Loizzo et al., 2019). Astiasarán and Candela (2000) reported a comparable study on PUFAs $(\mathrm{C} 18: 2 \mathrm{c} 9,12)$ content of various vegetable oils, i.e. soy oil which obtained 48.7\%, corn oils (47.7\%), sesame oils (44.5\%), sunflower oil (49.7\%), olive oil ranging from $3.5-21 \%$ and cotton oils with $50 \%$. These values are all significantly lower than the values obtained in this current study, implying that cactus pear is the best in terms of oil PUFA yield. PUFAs are able to alleviate symptoms of diseases such as coronary heart disease, stroke and rheumatoid arthritis.

The highest amount of C18:1c9 was detected for American Giant with $16.37 \%$ compared with Gymno Carpo, which demonstrated the lowest amount with $12.22 \%$. Robusta contained $13.46 \% \mathrm{C} 18: 1 \mathrm{c} 9$. The highest value for vaccenic acid (C18:1 n-7) (C18:1c7) was observed for Meyers (6.53\%) and the lowest for American Giant (5.14\%). Robusta (O. robusta) obtained 5.48\%. Loizzo et al. (2019) reported values ranging from $15.8-18.1 \%$ for $\mathrm{C} 18: 1 \mathrm{c} 9$ from two O. ficus-indica cultivars (red and yellow) extracted by two different methods (Soxhlet and UltrasoundAssisted). These authors reported values ranging between $4.3 \%$ and $5.1 \%$ for $\mathrm{C} 18: 1 \mathrm{c} 7$. The values for C18:1c9 reported by these authors were higher than in the current study, while the C18:1c7 values were somewhat lower than the current study's values. Ciriminna et al. (2017) obtained a higher content of vaccenic acid (6.29\%) for yellow Sicilian Opuntia ficus-indica seed oil, while Chougui et al. (2013) reported no vaccenic acid in yellow Algerian fruit. A vaccenic acid content of $4.83 \%$ was reported by Tlili et al. (2011) for Tunisian cactus pears. Interestingly, seed oil from O. ficus-indica from Marocco had no oleic acid (Ghazi et al., 2013).

The saturated fatty acid (SFA) palmitic acid (C16:0) ranged between 10.97 and $15.07 \%$ and stearic acid (C18:0) ranged between 2.62 and $3.74 \%$. American Giant obtained the lowest content of C16:0 (Table 1) and the highest oil percentage (Figure 1). These C16:0 values are slightly lower than those reported by de Wit et al. (2017) which ranged between 12.90 and $17.83 \%$ (Monterey and Nudosa, respectively) and the range reported by de Wit et al. (2018) namely $12.72-16.05 \%$. The C18:0 content varied between 2.62\% (Gymno Carpo) and $3.74 \%$ (American Giant) (Table 1), indicating only slight variation in C18:0 levels. Similar values were reported for chemically extracted oil as reported by 
TABLE 2. Fatty acid ratios of oil from 12 selected cold-pressed cactus pear cultivars (fatty acids were expressed as the proportion of each individual fatty acid to the total of all fatty acids present in the sample). Values in the Table are mean $\pm \mathrm{SD}$ of triplicate analyses.

\begin{tabular}{lcccccc}
\hline Cultivar & $\begin{array}{c}\text { Saturated fatty } \\
\text { acids (SFA) }\end{array}$ & $\begin{array}{c}\text { Monounsaturated } \\
\text { fatty acids (MUFA) }\end{array}$ & $\begin{array}{c}\text { Polyunsaturated } \\
\text { fatty acids (PUFA) }\end{array}$ & \multicolumn{2}{c}{$\begin{array}{c}\text { Omega-6 fatty } \\
\text { acids }\end{array}$} & $\begin{array}{c}\text { Omega-3 Fatty } \\
\text { acids }\end{array}$ \\
\hline Algerian & $15.96 \pm 0.06$ & $20.34 \pm 0.05$ & $63.70 \pm 0.10$ & $63.42 \pm 0.09$ & $0.28 \pm 0.14$ & $3.99 \pm 0.02$ \\
American Giant & $15.13 \pm 0.04$ & $22.00 \pm 0.01$ & $62.87 \pm 0.05$ & $62.64 \pm 0.18$ & $0.23 \pm 0.14$ & $4.16 \pm 0.01$ \\
Ficus-Indice & $15.27 \pm 0.05$ & $22.58 \pm 0.06$ & $62.15 \pm 0.01$ & $61.78 \pm 0.01$ & $0.37 \pm 0.01$ \\
Gymno Carpo & $16.21 \pm 0.06$ & $19.13 \pm 0.03$ & $64.67 \pm 0.03$ & $64.21 \pm 0.03$ & $0.46 \pm 0.01$ \\
Meyers & $15.94 \pm 0.16$ & $23.10 \pm 0.25$ & $60.87 \pm 0.07$ & $60.83 \pm 0.28$ & $0.20 \pm 0.18$ & $3.99 \pm 0.02$ \\
Morado & $15.91 \pm 0.07$ & $20.24 \pm 0.04$ & $63.85 \pm 0.04$ & $63.40 \pm 0.07$ & $0.46 \pm 0.07$ \\
Nudosa & $18.50 \pm 0.05$ & $22.28 \pm 0.24$ & $59.23 \pm 0.24$ & $58.78 \pm 0.20$ & $0.45 \pm 0.07$ & $3.20 \pm 0.02$ \\
Ofer & $15.83 \pm 0.19$ & $21.84 \pm 0.05$ & $62.32 \pm 0.14$ & $61.96 \pm 0.14$ & $0.37 \pm 0.01$ \\
Robusta & $14.96 \pm 0.17$ & $19.48 \pm 0.14$ & $65.55 \pm 0.31$ & $65.32 \pm 0.12$ & $0.24 \pm 0.19$ & $4.38 \pm 0.07$ \\
Tormentosa & $15.66 \pm 0.04$ & $21.69 \pm 0.05$ & $62.65 \pm 0.08$ & $62.27 \pm 0.09$ & $0.37 \pm 0.01$ & $4.00 \pm 0.01$ \\
Van As & $15.18 \pm 0.10$ & $23.14 \pm 0.1$ & $61.68 \pm 0.10$ & $61.43 \pm 0.11$ & $0.25 \pm 0.20$ & $4.06 \pm 0.02$ \\
Zastron & $14.76 \pm 0.07$ & $19.12 \pm 0.15$ & $66.13 \pm 0.11$ & $65.84 \pm 0.07$ & $0.28 \pm 0.24$ & $4.48 \pm 0.02$ \\
\hline
\end{tabular}

Values in the Table are mean $\pm \mathrm{SD}$ of triplicate analyses.

de Wit et al. (2017) (2.21-3.39\%) and de Wit et al. (2018) (2.4-4.01\%). These results are in agreement to those of Loizza et al. (2019) who found that fatty acid content is not affected by extraction method but by variety. Interestingly, Regalado-Rentería et al. (2018) found that oil extracted by cold-pressing was richer in UFA and poorer in SFA than oils extracted with solvents. Regarding SFA, the palmitic acid (5.12\%) and stearic acid (7.51\%) found in $O$. dillenii presented the main saturated fatty acid $(>22 \%)$. These are even higher than the SFA found in soy $(\sim 3 \%)$ (Ali Alsaad et al., 2019). Stearic acid has a neutral effect on LDL.

\subsubsection{Fatty acid ratios}

According to Table 2 SFA ranged from 14.76 (Zastron) to $18.50 \%$ (Nudosa). The results for the fatty acid composition presented in Table 1 show that C16:0 and C18:0 were observed to be marginally lower than those reported in the publication of de Wit et al. (2017) (16.59-20.65\%) and de Wit et al. (2018) (16.19-19.12\%) yet higher than those obtained by Ennouri et al. (2005). These fatty acids will influence SFA ratios, since they are the main contributors to SFA. The stage of development of the fruit may be the cause of variation in fatty acid composition, but in this study the fruits were all picked at the same maturity stage (50\% color break), although genotype, climate and weather, as well as environmental effects may be the reason behind this variation. According to de Wit et al. (2017), weather conditions, particularly were the main factors contributing to variations in fatty acid composition and oil percentage.

Total MUFA ranged between 19.12 and $23.10 \%$, which corresponds to that reported by de Wit et al. (2017) (15.78-23.30\%) and de Wit et al. (2018) (17.4-23.61\%). Gymno Carpo and Zastron obtained the lowest MUFA contents (19.13\% and 19,12\%) (Table 2), while Meyers and Van As showed the highest contents of MUFA (23.14\% and $23.10 \%$ ), respectively. MUFA, such as $\mathrm{C} 18: 1 \mathrm{c} 9$, ranged between 12.22\% (Gymno Carpo) and 16.07\% (Van As) (Table 1). Oil containing high concentration of $\mathrm{C} 18: 1 \mathrm{c} 9$ has been reported to be more stable to oxidation, which is desired for improved shelf-life (Lajara et al., 1990).

PUFA was established as the most prominent fatty acid ratio ranging between 59.23 (Nudosa) and $66.13 \%$ (Zastron). PUFA from de Wit et al. (2017) was at the lower range and ranged from $55.98-67.62 \%$. C18:2c9,12 was established as the dominating PUFA with the lowest level of $58.56 \%$ for Nudosa and the highest level of $65.18 \%$ for Robusta (Table 1), with $\mathrm{C} 20: 3 \mathrm{c} 9,12,15(0.22$ to $0.35 \%)$ and $\mathrm{C} 20: 3 \mathrm{c} 8,11,14$ $(0.13$ to $0.22 \%)$ occurring at very low levels. 
Cold-pressed cactus pear seed oil: Quality and stability $\bullet 9$

TABLE 3. Physicochemical properties of oil from 12 selected cold-pressed cactus pear cultivars analyzed one week after pressing.

\begin{tabular}{|c|c|c|c|c|c|c|c|c|c|c|}
\hline Cultivar & $\begin{array}{l}\text { Peroxide Value } \\
\text { (meq 02/1000 g fat) }\end{array}$ & $\begin{array}{c}\text { \% Free Fatty } \\
\text { Acids }\end{array}$ & $\begin{array}{c}\rho \text {-Anisidine } \\
\text { value (mmol/kg) }\end{array}$ & $\begin{array}{l}\text { Refraction } \\
\text { Index at } 40^{\circ} \mathrm{C}\end{array}$ & Iodine Value & $\begin{array}{c}\beta+\gamma \\
\text { Tocopherol } \\
(\mathrm{mg} / \mathbf{1 0 0 g})\end{array}$ & ORAC $^{1}$ & $\mathrm{OSI}^{2}$ & $\begin{array}{l}\text { Induction Time } \\
\text { extrapolated to } \\
25^{\circ} \mathrm{C} \text { (Years) }\end{array}$ & $\begin{array}{c}\text { Induction Time } \\
\text { extrapolated to } \\
30^{\circ} \mathrm{C} \text { (Years) }\end{array}$ \\
\hline Algerian & $4.23 \pm 0.48$ & $3.21 \pm 0.04$ & $4.08 \pm 0.37$ & $1.4666 \pm 0.0001$ & $121.60 \pm 4.12$ & $58.27 \pm 2.47$ & $5.28 \pm 0.43$ & $2.31 \pm 0.14$ & $0.52 \pm 0.01$ & $0.35 \pm 0.01$ \\
\hline $\begin{array}{l}\text { American } \\
\text { Giant }\end{array}$ & $3.02 \pm 0.02$ & $1.21 \pm 0.03$ & $1.37 \pm 0.14$ & $1.4666 \pm 0.0001$ & $125.45 \pm 2.09$ & $54.19 \pm 2.96$ & $4.70 \pm 0.25$ & $2.19 \pm 0.04$ & $3.44 \pm 0.01$ & $2.08 \pm 0.01$ \\
\hline Ficus-Indice & $3.65 \pm 0.18$ & $2.19 \pm 0.06$ & $2.73 \pm 0.21$ & $1.4666 \pm 0.0001$ & $123.84 \pm 2.09$ & $59.36 \pm 7.61$ & $4.54 \pm 0.27$ & $3.17 \pm 0.09$ & $0.73 \pm 0.01$ & $0.49 \pm 0.01$ \\
\hline Gymno Carpo & $5.87 \pm 0.02$ & $2.32 \pm 0.01$ & $1.00 \pm 0.02$ & $1.4666 \pm 0.0001$ & $122.32 \pm 0.60$ & $55.43 \pm 6.05$ & $4.10 \pm 0.25$ & $2.54 \pm 0.01$ & $2.69 \pm 0.01$ & $1.66 \pm 0.01$ \\
\hline Meyers & $4.81 \pm 0.12$ & $1.63 \pm 0.03$ & $1.42 \pm 0.32$ & $1.4664 \pm 0.0003$ & $123.07 \pm 1.17$ & $59.78 \pm 2.04$ & $3.87 \pm 0.06$ & $1.88 \pm 0.01$ & $4.15 \pm 0.01$ & $2.46 \pm 0.01$ \\
\hline Morado & $4.19 \pm 0.24$ & $1.15 \pm 0.01$ & $1.40 \pm 0.42$ & $1.4666 \pm 0.0001$ & $123.32 \pm 0.28$ & $61.31 \pm 3.33$ & $4.01 \pm 0.18$ & $2.46 \pm 0.06$ & $2.14 \pm 0.01$ & $1.33 \pm 0.01$ \\
\hline Nudosa & $4.49 \pm 1.24$ & $1.74 \pm 0.09$ & $1.58 \pm 0.12$ & $1.4659 \pm 0.0001$ & $123.92 \pm 6.36$ & $51.69 \pm 4.26$ & $4.14 \pm 0.09$ & $2.95 \pm 0.10$ & $2.74 \pm 0.01$ & $1.69 \pm 0.01$ \\
\hline Ofer & $4.72 \pm 0.01$ & $1.19 \pm 0.02$ & $1.64 \pm 0.36$ & $1.4666 \pm 0.0001$ & $122.64 \pm 1.18$ & $61.47 \pm 1.65$ & $4.30 \pm 0.49$ & $2.92 \pm 0.02$ & $1.64 \pm 0.01$ & $1.04 \pm 0.01$ \\
\hline Robusta & $5.06 \pm 0.78$ & $3.41 \pm 0.09$ & $1.95 \pm 0.54$ & $1.4665 \pm 0.0002$ & $122.85 \pm 3.85$ & $55.30 \pm 9.38$ & $5.07 \pm 0.51$ & $2.25 \pm 0.01$ & $3.56 \pm 0.01$ & $2.16 \pm 0.01$ \\
\hline Tormentosa & $5.80 \pm 0.38$ & $3.22 \pm 0.03$ & $0.98 \pm 0.54$ & $1.4664 \pm 0.0001$ & $120.58 \pm 2.22$ & $58.45 \pm 4.70$ & $4.20 \pm 0.41$ & $1.91 \pm 0.08$ & $9.40 \pm 0.01$ & $5.30 \pm 0.01$ \\
\hline Van As & $3.60 \pm 0.41$ & $4.30 \pm 0.02$ & $2.94 \pm 0.17$ & $1.4664 \pm 0.0001$ & $120.59 \pm 1.93$ & $59.95 \pm 5.74$ & $5.08 \pm 0.22$ & $1.78 \pm 0.08$ & $2.14 \pm 0.01$ & $1.31 \pm 0.01$ \\
\hline Zastron & $5.72 \pm 0.58$ & $2.75 \pm 0.06$ & $1.94 \pm 0.55$ & $1.4668 \pm 0.0001$ & $127.43 \pm 1.13$ & $56.70 \pm 1.37$ & $5.37 \pm 0.05$ & $1.74 \pm 0.07$ & $4.73 \pm 0.01$ & $2.76 \pm 0.01$ \\
\hline
\end{tabular}

Values in the Table are mean $\pm \mathrm{SD}$ of triplicate analyses.

1 Oxygen radical antioxidant capacity ( $\mu$ mol Trolox equivalents/g)

2 Oxidative stability Index at $110{ }^{\circ} \mathrm{C}$ (Hour)

Omega-6 (n-6) fatty acids ranged from 58.78$65.84 \%$ (Nudosa and Zastron, respectively). All the cultivars, with the exception of Nudosa, contained $\mathrm{n}-6$ contents at above $60 \%$. Nudosa attained the lowest concentration of $\mathrm{n}-6$ fatty acid ratio with $58.78 \%$ (Table 2). Zastron had the highest contents of PUFA and $n-6$ but obtained the lowest content of MUFA. These contents were found to be slightly higher compared to results from de Wit et al. (2017) (55.98 - 67.45\%). Pardo et al. (2009) concluded that cactus pear seed oils are good sources of omega- 6 fatty acids.

The omega-3 (n-3) fatty acid ratio occurred at very low levels (Table 2 ). The contents ranged from 0.20 (Meyers) - $0.46 \%$ (Gymno Carpo), respectively. Omega-3 (n-3) fatty acids, such as C18:3c9,12,15 $(\mathrm{C} 18: 3 \mathrm{n}-3)$ occurred at a very low level and ranged from $0.18-0.36 \%$ (Meyers and Morado in Table 2).

The PUFA/SFA ratio is used to measure the level of unsaturation and is taken as an instrument to measure the oil's tendency to undergo autoxidation. The PUFA/SFA ratio ranged from 3.20 - 4.48\% with Zastron occurring in the highest amount and Nudosa at the lowest level (Table 2). American Giant, FicusIndice, Morado, Robusta, Tormentosa, van As and Zastron also attained PUFA/SFA contents above $4 \%$. Zastron was also amongst those that had the highest content of C18:2c9,12, while Nudosa occurred at the lowest level (Table 1). O. dillenii presented a ratio of 3.22 .

The results for the physicochemical properties of the oil from cactus pear cultivars are presented in Table 3.

\subsubsection{Refraction index (RI)}

The RI values of the oils increase as a result of autoxidation. The RI depends on the chemical composition and temperature of the oil. It also increases with degree of saturation (Brahmi et al., 2020) and secondary functions on fatty acid chains. As indicated by the RI values presented in Table 3, little differences were observed among the RI values for all cultivars. The RI values ranged from 1.4659-1.4668 (Nudosa and Zastron). The higher the level of unsaturation, the higher the levels of RI and IV, for example, Zastron obtained the highest RI value (1.4668) and high PUFA content (66.08\%) as well as high IV (127.43). Oils with a high unsaturation degree are more likely to undergo autoxidation and tend to oxidize easily when used at high temperatures, for example, PUFA (C18:2c9,12) oxidized \pm 50 times faster than C18:1c9 (MUFA). Therefore, an increased RI value could be expected as a result of exposure to heat and light.

American Giant and Gymno Carpo were also amongst the cultivars with high PUFA, RI value and 
IV value (Tables 2 and 3). Furthermore, the higher the MUFA content (C18:1c9), the lower the RI and IVvalues, for example, Van As attained a higher content of MUFA (23.14\%), a low RI value of 1.4664 as well as a low IV value of 120.59 (Tables 2 and 3). These results fall within a similar range (1.464 RI) to those reported by Gharby et al. (2011). Previous literature reported a higher RI value of 1.4831 in cactus pear seed oil, 1.473 in rape seed oil, and 1.475 in Opuntia ficus-indica (Ennouri et al., 2005). Other studies reported slightly lower RI values ranging between 1.4658 and 1.4676 (de Wit et al., 2017).

Valuable information can be obtained by determining the density of the oils. Density gives information on the nature of fatty acids, such as chain length, unsaturation degree, and functional groups. Density will also be influenced by the composition and temperature of the oil. Together with RI, it can also indicate the purity of the oil (Brahmi et al., 2020). It is therefore recommended to include density analyses in future studies.

\subsubsection{Iodine value (IV)}

Iodine value is an indication of the total number of double bonds. The iodine value (IV) ranged from 120.58-127.43 (Tormentosa and Zastron). Zastron obtained the highest IV (number of gram iodine absorbed by $100 \mathrm{~g}$ of oil) of 127.43 followed by American Giant (125.45), Morado (123.32) and Nudosa (123.92). Tormentosa recorded the lowest IV of 120.58 (Table 3). According to Table 2, Zastron and American Giant attained the highest PUFAs (high unsaturation level) as well as high IV and low MUFA content while Nudosa obtained the smallest content of PUFA. The values in this study are higher than those reported by Karleskind and Wolff(1992) ranging from 105.5-107.38 (cactus pear seed oils). De Wit et al. (2017) reported slightly lower iodine values ranging between 110.68 (Nudosa) and 126.82 (Robusta).

Since IV measures the unsaturation of oils, it can also be an indication of the stability of the oil since a high degree of unsaturation suggests a high susceptibility to oxidation. Low IV therefore indicates more resistance to oxidation because of increased saturation and vice versa (de Wit et al., 2017).

\subsubsection{Tocopherols}

Vegetable oils are the most important dietary source of tocopherols. Tocopherols are phenolic compounds that are naturally occurring antioxidants that present biological activity (Ali Alsaad et al., 2019). Fernández-Martinez et al. (2004) indicated that fatty acids, natural antioxidants, tocopherols and sterols are the key constituents that define oil quality. Normand et al. (2006) stated that oils with high tocopherols have greater stability to oxidation. Tocopherols are natural antioxidants in plant foods, particularly those that contain high levels of PUFA as they are able to scavenge lipid peroxyl radicals of unsaturated lipid molecules, inhibiting the propagation of lipid peroxidation.

$\beta$ and $\gamma$ tocopherols ranged between 61.47 and $51.69 \mathrm{mg} / 100 \mathrm{~g}$ (Table 3). Ofer obtained a higher content of $\beta$ and $\gamma$ tocopherols $(51.69 \mathrm{mg} / 100 \mathrm{~g}$ ) followed by Morado $(61.31 \mathrm{mg} / 100 \mathrm{~g})$, which means that Ofer and Morado will be more stable to oxidation compared to Nudosa $(51.69 \mathrm{mg} / 100 \mathrm{~g})$. The values obtained in the current study are comparable to those reported by Chu et al. (2002) with cold-pressed cactus pear seed oil at $94.6 \mathrm{mg} / 100 \mathrm{~g}$, argan oil at $85.0 \mathrm{mg} / 100 \mathrm{~g}$, olive oil at $22.0 \mathrm{mg} / 100 \mathrm{~g}$, soybean at $65.0 \mathrm{mg} / 100 \mathrm{~g}$ and sunflower oil at $49.0 \mathrm{mg} / 100 \mathrm{~g}$. Morales et al. (2012) found values of 140-220 $\mu \mathrm{g} / 100 \mathrm{~g}$.

Tocopherol contents are influenced by the extraction method (Loizzo et al., 2019). Red cultivars were found to contain higher contents than the yellow cultivars and were mainly in the form of $\gamma$-tocopherol. In Moroccan cactus pear seed oil, vitamin $\mathrm{E}$ was only present as $\gamma$-tocopherol (1.23\%) (Ghazi et al., 2013). Regalado-Rentería et al. (2018) found a tendency for metabolites such as $\gamma$-tocopherol to be higher in cold-pressed oils than oils extracted with solvents. These authors reported $\gamma$-tocopherol values between 1.71 and $13.86 \mathrm{mg} / 100$ $\mathrm{g}$ oil. During the analysis of anti-inflammatory compounds of $O$. ficus-indica seed oils from SaudiArabia, $\beta$-tocopherol contents of $1.56 \%$ were found. This oil was extracted with hexane (Boshak et al., 2020).

\subsubsection{Oxygen radical antioxidant capacity (ORAC)}

Lipid oxidation is a process which is initiated by free radical reactions at the double bonds of unsaturated fatty acids and has been reported to be the key factor in the quality deterioration of edible oils since it modifies the chemical, sensory and nutritional properties of the oils. Márquez- 
Ruiz et al. (1996) pointed out that autoxidation is another key factor that leads to the development of quality loss in refined oils during storage. The 2,2-diphenyl-1-picrylhydrazyl (DPPH) assay is normally used to predict the stability of cold-pressed oils against oxidation. Most of the literature cited included the use of the DPPH and 2,2'-azino-bis3-ethylbenzthiazoline-6-sulphonic acid (ABTS) methods. Cao et al. (1996) reported the determination of total antioxidant capacity using the ORAC method, which is currently being used to determine the total antioxidant capacity and measures the plant extract's ability to scavenge peroxyl radicals.

The oxidation of oils happens mainly at the sites of unsaturation and the oxidation rate mainly depends on the number of double bonds and their positions. Table 3 shows that Zastron had the highest antioxidant capacity with an ORAC value of $5.37 \mu \mathrm{mol} / \mathrm{g}$, followed by Algerian with $5.28 \mu \mathrm{mol} / \mathrm{g}$. Meyers had the lowest antioxidant capacity $(3.87 \mu \mathrm{mol} / \mathrm{g})$. Kuti (2004) reported higher values which ranged from 1.6$15.8 \mathrm{mMTE} / \mathrm{g}$ in yellow-skinned fruits and 1.7-49.2 $\mathrm{mMTE} / \mathrm{g}$ in the purple-skinned fruits.

It was found by Ramírez-Moreno et al. (2017) that extraction solvent had a significant effect on the free radical scavenging capacity of the seed oil and that the green $O$. ficus-indica variety had a higher antioxidant activity regardless of the solvent used. The antioxidant activity of $O$. ficus-indica seed oil from Saudi-Arabia (Brahmi et al., 2020) showed a lower DPPH value in cold-pressed oil than in oils extracted by the Soxhlet method. Antioxidant activity was strongly correlated with the amounts of phenolic compounds, including polyphenols and flavonoids. $O$. dillenii seed oil from Iraq demonstrated a strong antioxidant capability due to its ability to reduce oxidation as determined by the DPPH method (Ali Alsaad et al., 2019), which reinforced the effect of variety on antioxidant activity.

\subsection{Determination of oxidative stability}

\subsubsection{Free fatty acids (FFA)}

The level of free fatty acids (FFA) in oils is measured by the acid value (AV) generated upon the hydrolytic degradation of lipid particles and is therefore an indicator of hydrolytic activity, which consequently adds to the decrease in the time span of usability of the oil. The maximum FFA content limit recommended for cold-pressed oil is $8 \%$, $0.3 \%$ for refined oils and $5 \%$ for virgin palm oils according to the Codex Alimentarius Commission standard (Codex Alimentarius Commission, 2009). According to the results presented in Table 3, the FFA content ranged between 1.15 and $4.30 \%$ (Morado and Van As) and the \% FFA of all cultivars was within the recommended limit, implying that cactus pear seed oil is of good quality from a FFA point of view. In a previous study, \% FFA ranged between 2.49 and $5.08 \%$ in chemically extracted oil (de Wit et al., 2017). The content in cold-pressed oil was thus lower. The production of FFA is a result of lipid hydrolysis which is triggered by chemical or enzymatic actions. Increased free fatty acid values are indicators of increased primary oxidation. Factors such as high temperature and humidity are accountable for an increase in FFA content in oils. An elevated acidity value of $21.2 \%$ was reported by Brahmi et al. (2020) for Algerian cold-pressed $O$. ficus-indica seed oil. This high value could be ascribed to the enzymatic hydrolysis of seeds during oil pressing, handling or processing, as well as elevated temperatures and the presence of water during the process. It was also mentioned by the authors that free fatty acids could be present since no refining of the oil took place, which could possibly remove acids as impurities.

\subsubsection{Peroxide value (PV)}

Martín-Polvillo et al. (2004) reported that peroxide value (PV) measures the level of hydroperoxide in the oil and is a valuable tool for the indication of a commencement period of oxidation. Furthermore, PV reaches the highest level during the progression of oxidation and following this stage (secondary oxidation), the decomposition rate of hydroperoxides surpasses the rate of their development. Peroxide value is also used to test oxidative rancidity in oils and fats (Karleskind and Wolff, 1992). It was reported that the acceptable PV value for cold pressed oil is $<15 \mathrm{meq} \mathrm{O}_{2} \cdot \mathrm{kg}^{-1}$ (Codex Alimentarius Commission, 1999). According to the results presented in Table 3, all cultivars attained $\mathrm{PV}$ values of $<15$ meq $\mathrm{O}_{2} \cdot \mathrm{kg}^{-1}$, therefore $\mathrm{PV}$ value results are in agreement with the recommended value for cold-pressed oil of good quality.

PV ranged between 3.02 and 5.87. Although Gymno Carpo and Tormentosa were amongst the 
cultivars with higher PV values (5.87 and 5.80), oxidation had not yet occurred in these cultivars since their PV values were still within the recommended limit of $<15$ meq $\mathrm{O}_{2} \cdot \mathrm{kg}^{-1}$, which indicates that a rancid taste was not yet noticeable (Table 3). Salvo et al. (2002) pointed out that a rancid taste in oils begins to be noticeable at PV values of $20-40 \mathrm{meq} \mathrm{O}_{2} \cdot \mathrm{kg}^{-1}$. PUFAs are more susceptible to oxidation than MUFA and SFA. The higher PVs observed for Gymno Carpo and Tormentosa were probably a consequence of their higher unsaturation levels (Tables 1 and 2). American Giant had on average a PV of 3.02 meq $\mathrm{O}_{2} \cdot \mathrm{kg}^{-1}$, which was the lowest compared to that of the other cultivars. Van As also had a relatively low PV value of 3.60 (Table 3). De Wit et al. (2017) reported PV values of chemically extracted cactus pear oils which were above the recommended limit and ranged between 9.5 and $23.30 \mathrm{meq} \mathrm{O}_{2} \cdot \mathrm{kg}^{-1}$.

Karleskind and Wolff (1992) reported PV estimations of margarine containing Opuntia ficusindica oil which were far below the levels permitted by the international benchmarks and ranged between 0.38 and 0.39 meq $\mathrm{O}_{2} \cdot \mathrm{kg}^{-1}$. PV measures the extent of rancidity reactions during storage, and therefore indicates quality and stability. A PV of 12 meqO$_{2} /$ $\mathrm{kg}$ was reported for Algerian O. ficus-indica coldpressed seed oils (Koshak et al., 2020). PV is therefore affected by genetics, cultivars, growth conditions, soil geography, and harvesting routines as well as handling and storage.

\subsection{3. $\rho$ - Anisidine value ( $\rho-A V)$}

The $\rho-\mathrm{AV}$ was taken as a tool used to quantify secondary oxidation by surveying the measurement of unsaturated aldehydes as a result of the decomposition of hydroperoxides (Shahidi and Zhong, 2005). The $\rho$-AV is an indicator of oxidative rancidity in oils. The results presented in Table 3 demonstrate that the $\rho$-AV ranged between $0.98-4.08 \mathrm{mmol} / \mathrm{kg}$ for Tormentosa and Algerian, respectively. Algerian had the highest $\rho$-AV of 4.08 followed by Van As with $\rho$-AV of 2.94 $\mathrm{mmol} / \mathrm{kg}$. Tormentosa acquired the lowest $\rho$-AV content of $0.99 \mathrm{mmol} / \mathrm{kg}$. The results demonstrated that there were only small differences among the $\rho$-AV of American Giant (1.37), Morado (1.40), Ofer (1.64) and Nudosa (1.58). Algerian recorded the highest $\rho$-Anisidine value and $\mathrm{PV}$ value, which is indicative of secondary oxidation products. The high $\rho$-AV may be due to their higher level of unsaturation.
The recommended $\rho$-Anisidine value ( $\rho$-AV) limit is $<10.0 \mathrm{mmol} / \mathrm{kg}$ (Codex Alimentarius Commission, 1999). The $\rho-\mathrm{AV}$ values obtained were within the acceptable limit (Table 3 ). Some of these $\rho$-AV values were higher than those reported in the literature which ranged from $0.02-3.73 \mathrm{mmol} / \mathrm{kg}$ (de Wit et al., 2017). Aldehydes made up the highest percentage of cactus pear seed oil volatiles (Karabagias et al., 2020). Aldehydes are responsible for, among others, acrid, burnt-fat, fruit-like, fermented, nutty, deep fat, butter, chicken and fusty odors, flavors and smells. The butyric acid reported by Karabagias et al. (2020) is responsible for the buttery flavor of the cactus pear seed oil.

\subsubsection{Oxidative stability index}

The OSI value gives an indication of the resistance of lipids to oxidation and is also used for quality control of the oils, as well as an indication of the shelf-life of oils. The shorter the reaction time, the more susceptible the oil is to oxidation and therefore higher values will imply more resistance to oxidation. The values ranged between 1.78 and 3.17 $\mathrm{h}$ and were lower than the values obtained by de Wit et al. (2017), which ranged between 1.79 and 4.15 h. Ficus-Indice had the highest OSI value of 3.17 hours at $110{ }^{\circ} \mathrm{C}$ followed by Nudosa (2.92 hours) and Ofer (2.92 hours), implying that these cultivars were more resistant to oxidation reactions. Van As, which attained the highest content of C18:1c9 (Table 1), was determined to be the most favored oil since it is rich in oleic acid and oils rich in C18:1c9 have potential for combining the hypocholesterolemic effect and greater oxidative stability. Oils which are high in MUFA (C18:1c9) such as Nudosa (Table 2) are less susceptible to oxidative degradation and in this manner indicate potential for applications requiring high oxidative stability. Gharby et al. (2011) reported OSI of 7 hours at $110^{\circ} \mathrm{C}$ for Opuntia ficus-indica, 31.23 hours for argan, 7.5 hours for olive oil and 5 hours for soybean and sunflower oil.

\subsubsection{Extrapolation of induction time}

Induction time extrapolated to 25 and $30{ }^{\circ} \mathrm{C}$ was done to predict the shelf-life of the oils based on OSI using Rancimat induction times (Rancimat Manual, 2009). The induction period is an indication of how long the oils will take to reach an end point or be 


\section{Extrapolation (Induction time)}
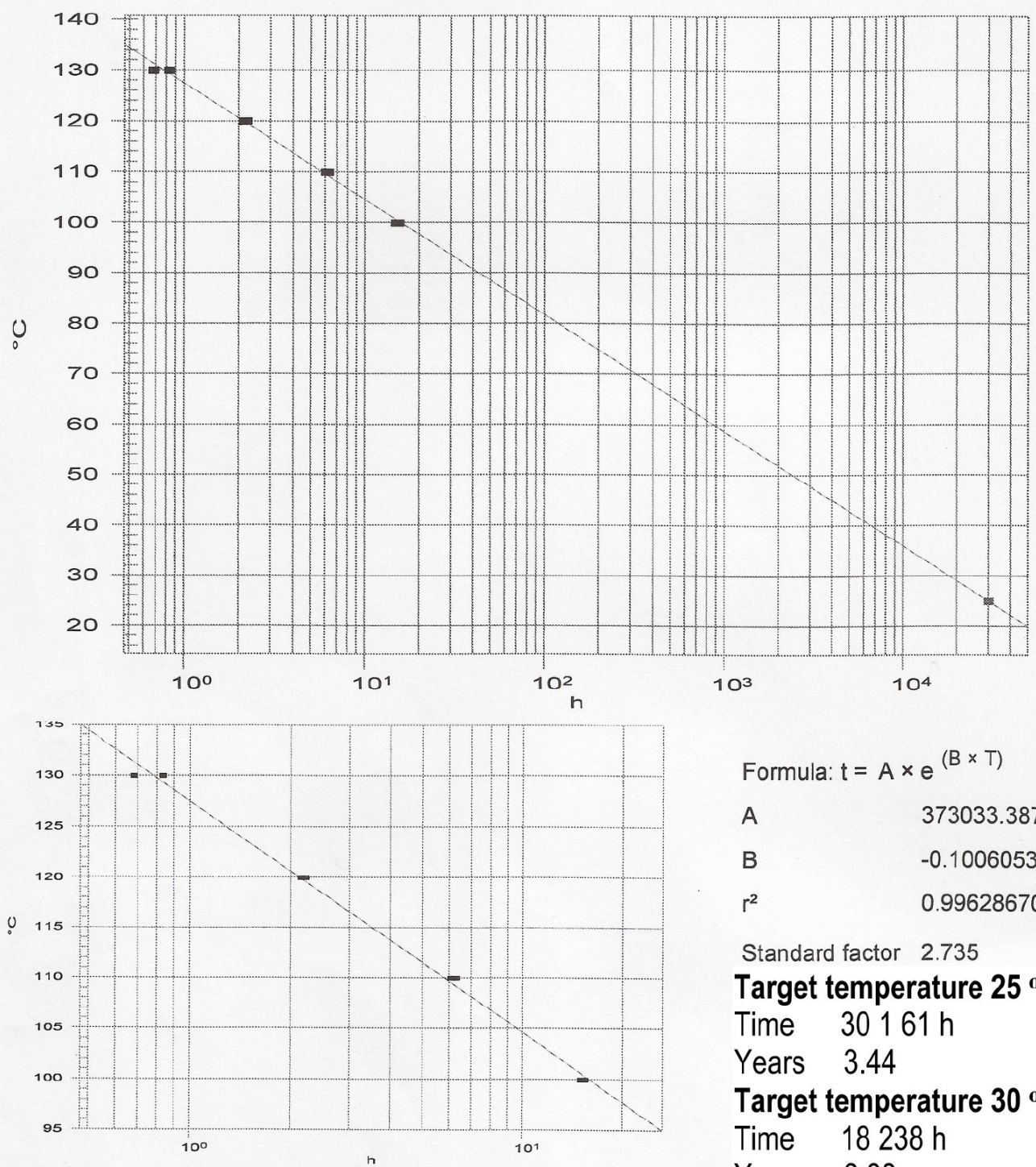

Formula: $t=A \times e^{(B \times T)}$

373033.387617813

B

$-0.100605381170435$

$r^{2}$

0.996286703130836

Standard factor 2.735

Target temperature $25^{\circ} \mathrm{C}$

Time $30161 \mathrm{~h}$

Years 3.44

Target temperature $30{ }^{\circ} \mathrm{C}$

Time $18238 \mathrm{~h}$

Years 2.08

ID 1

ID 2

Temperature

Result

2B-100

2B-American Giant-100

$100^{\circ} \mathrm{C}$

$14.92 \mathrm{~h}$

$2 A-100$

2A-American Giant-100

$100^{\circ} \mathrm{C}$

$15.45 \mathrm{~h}$

2B-110

2B-American Giant-110

$110^{\circ} \mathrm{C}$

$6.31 \mathrm{~h}$

$2 A-110$

2A-American Giant-110

$110^{\circ} \mathrm{C}$

$6.08 \mathrm{~h}$

2B-120

2B-American Giant-120

$120^{\circ} \mathrm{C}$

$2.15 \mathrm{~h}$

$2 A-120$

2A-American Giant-120

2B-130

2B-American Giant-130

$120^{\circ} \mathrm{C}$

$2.22 \mathrm{~h}$

$2 A-130$

2A-American Giant-130

$130^{\circ} \mathrm{C}$

$0.83 \mathrm{~h}$

$130^{\circ} \mathrm{C}$

$0.68 \mathrm{~h}$

FIGURE 2. Predicted shelf-life of American Giant cold-pressed cactus pear seed oil stored at 25 and $30^{\circ} \mathrm{C}$. The extrapolation function of the Rancimat 743 apparatus was used to predict induction times at 25 and $30^{\circ} \mathrm{C}$ according to the formula: Predicted induction time $=\mathrm{AX} \mathrm{e}^{\text {(BXT) }}$ 
oxidized. American Giant is presented as an example in Figure 2. Induction time is also described as the time taken before the rapid increase in oxidation occurs and is used to make relative assessments on oxidative stability (Gharby et al., 2011).

The accelerated testing can then be extrapolated to real time conditions. Algerian was found to have a shorter induction time of 5 months, 2 weeks when extrapolated to $25^{\circ} \mathrm{C}$ and 3 months, 5 weeks when extrapolated to $30^{\circ} \mathrm{C}$, implying that Algerian will have a shorter shelf-life compared to Tormentosa, with an anticipated time span of usability of 9 years and 4 months when extrapolated to $25{ }^{\circ} \mathrm{C}$ and 5 years 3 months when extrapolated to $30^{\circ} \mathrm{C}$ (Table 3).

\subsection{Pearson correlation analysis}

A Pearson correlation analysis was conducted on fatty acid content, fatty acid ratios, physicochemical properties and OSI to establish the relationship among them (Table 4). A significant $(\mathrm{p}<0.001)$ negative correlation $(-0.6757)$ was observed between \% FFA and OSI (Table 4). This means that cultivars which recorded high contents in \% FFA had decreased OSI values or vice versa. This was observed in cultivars such as Algerian which attained a high content in \% FFA (3.21\%) and low OSI $(2.31 \mathrm{~h})$. Nudosa and Ofer possessed the lowest contents in \% FFA and obtained the highest OSI values of 2.95 and $2.92 \mathrm{~h}$. De Wit et al. (2017) reported higher \% FFA results ranging from $2.49 \%$ (Tormentosa) with OSI of $3.91 \mathrm{~h}-5.08 \mathrm{~h}$ (Algerian) with OSI of $4.15 \mathrm{~h}$ and the \% FFA was higher than the recommended limit, implying that there was increased primary oxidation. El Mannoubi et al. (2009) reported much lower \% FFA results for cactus pear oil with $0.64 \%$.

No significant correlations with OSI were observed for $\mathrm{PV}, \%$ Oil, $\rho$-Anisidine value, Refraction Index or $\beta+\gamma$ Tocopherols. A significant $(p<0.01)$ negative correlation $(-0.5762)$ was observed between OSI and ORAC. An increase in ORAC initiated a decrease in the OSI value. This correlation was especially observed in Zastron and Algerian, whereby high ORAC values were observed for these cultivars along with low OSI values. This correlation shows that these cultivars are less stable to oxidation due to their higher degree of unsaturation. Both $\mathrm{C} 16: 0, \mathrm{C} 16: 1 \mathrm{c} 9$ and $\mathrm{C} 17: 1 \mathrm{c} 10$ correlated significantly $(p<0.001, p=0.001$ and $p$ $<0.01$ ) with OSI, as in Nudosa, which obtained the highest content of $\mathrm{C} 16: 0(15.22 \%)$ and the highest content of SFA (18.68\%) (Tables 1 and 2).

A significant $(p<0.001)$ positive correlation (0.7409) was observed between C16:0 and OSI. This effect was observed for Nudosa, which obtained the highest content of C16:0 with $15.22 \%$ (Table 1) as well as the highest OSI value of $2.95 \mathrm{~h}$ (Table 3 ). A significant $(\mathrm{p}<0.001)$ positive correlation $(0.7230)$ was observed between OSI and SFA. An increase in SFA initiated an increase in OSI as in Nudosa, which had the highest SFA (18.68\%, Table 3) with a high OSI value (2.95 h, Table 3$)$.

C16:1c9 and $\mathrm{C} 17: 1 \mathrm{c} 10$ had a positive $(0.6522$ and 0.5690$)$ significant $(p=0.001$ and $p<0.01)$ correlation with the OSI. This effect was observed for Nudosa which obtained high C16:1c9 (0.75\%) and $\mathrm{C} 17: 1 \mathrm{c} 10(0.05 \%)$ contents with OSI value of 2.95h. A negative $(-0.7146)$ significant $(\mathrm{p}<0.001)$ correlation between PUFA/SFA and OSI value existed. This effect was observed for Zastron, Van As and American Giant, which possessed the highest contents of PUFA/SFA $(4.45 \%, 4.03 \%$ and $4.11 \%$, Table 2 ) and obtained the lowest value of OSI (1.74 h, $1.78 \mathrm{~h}$ and $2.19 \mathrm{~h}$, Table 3). With cold-pressing Algerian, American Giant and FicusIndice obtained the highest contents of $\mathrm{C} 18: 2 \mathrm{c} 9,12$ which resulted in a low oxidative stability index and made them less stable to oxidation. However, of these four cultivars, only American Giant had a low \% FFA. The reason for the low OSI is the \% FFA and the lower unsaturation level (secondary importance). Oil with high unsaturation is most likely to experience autoxidation.

As expected, a significant $(\mathrm{p}<0.001)$ positive correlation (0.9996) was observed between OSI and induction time extrapolated to $25^{\circ} \mathrm{C}$ and 30 ${ }^{\circ} \mathrm{C}$. The length of induction time depends on the level of unsaturation of oil. Tormentosa recorded the highest predicted shelf-life at 25 and $30^{\circ} \mathrm{C}$ and was also amongst those cultivars that obtained the high MUFA (C18:1c9) content (Tables 2 and 3). Oils with high MUFA contents (C18:1c9) are less susceptible to oxidation degradation and therefore these oils show great potential for applications requiring high oxidative stability.

$\rho$-Anisidine value had significant $(\mathrm{p}<0.01)$ negative correlations $(-0.5120$ and -0.5297$)$ with 
TABLE 4. Pearson correlation analysis of the of the fatty acid content, fatty acid ratios, physicochemical properties and oxidative stability index, induction time extrapolated to $25^{\circ} \mathrm{C}$ and induction time extrapolated to $30^{\circ} \mathrm{C}$ of oil from selected cold-pressed cactus pear cultivars.

\begin{tabular}{|c|c|c|c|c|c|c|}
\hline & \multicolumn{2}{|c|}{ OSI } & \multicolumn{2}{|c|}{$\begin{array}{l}\text { Induction time extrapolated } \\
\text { to } 25^{\circ} \mathrm{C}\end{array}$} & \multicolumn{2}{|c|}{$\begin{array}{c}\text { Induction time extrapolated } \\
\text { to } 30^{\circ} \mathrm{C}\end{array}$} \\
\hline & $\begin{array}{c}\text { Correlation } \\
\text { coefficient (r) }\end{array}$ & $\begin{array}{l}\text { Significance } \\
\text { level }(\mathbf{P})\end{array}$ & $\begin{array}{c}\text { Correlation } \\
\text { coefficient (r) }\end{array}$ & $\begin{array}{l}\text { Significance } \\
\text { level (P) }\end{array}$ & $\begin{array}{c}\text { Correlation } \\
\text { coefficient (r) }\end{array}$ & $\begin{array}{l}\text { Significance } \\
\text { level (P) }\end{array}$ \\
\hline \multicolumn{7}{|l|}{ Physicochemical properties: } \\
\hline OSI (Oxidative stability index) & 1.0000 & - & -0.4616 & 0.0154 & -0.4539 & 0.0174 \\
\hline Induction time extrapolated to $25^{\circ} \mathrm{C}$ & -0.4616 & 0.0154 & 1.0000 & - & 0.9996 & $\mathrm{P}<0.001$ \\
\hline Induction time extrapolated to $30^{\circ} \mathrm{C}$ & -0.4539 & 0.0174 & 0.9996 & 0.001 & 1.0000 & - \\
\hline$\%$ Oil & -0.1197 & 0.4869 & 0.1768 & 0.3024 & 0.1785 & 0.2975 \\
\hline PV (Peroxide Value) & -0.0620 & 0.7585 & 0.4585 & 0.0161 & 0.4569 & 0.0166 \\
\hline \% FFA (Free Fatty Acids) & -0.6757 & 0.0001 & 0.2063 & 0.3019 & 0.1915 & 0.3387 \\
\hline$\rho$-Anisidine value & -0.1927 & 0.3355 & -0.5120 & 0.0063 & -0.5297 & 0.0045 \\
\hline RI (Refraction Index) & -0.4080 & 0.0346 & -0.0312 & 0.8771 & -0.0351 & 0.8619 \\
\hline IV (Iodine Value) & -0.0209 & 0.9174 & -0.0180 & 0.9289 & -0.0086 & 0.9661 \\
\hline$\beta+\gamma$ Tocopherol & -0.1383 & 0.4915 & -0.0747 & 0.7113 & -0.0845 & 0.6753 \\
\hline $\begin{array}{l}\text { ORAC (Oxygen radical antioxidant } \\
\text { capacity) }\end{array}$ & -0.5762 & 0.0017 & -0.1644 & 0.4125 & -0.1749 & 0.3828 \\
\hline \multicolumn{7}{|l|}{ Fatty acid composition (\%) } \\
\hline C14:0 (Myristic acid) & 0.2984 & 0.1306 & -0.2782 & 0.1600 & -0.2819 & 0.1542 \\
\hline C16:0 (Palmitic acid) & 0.7409 & 0.001 & -0.3072 & 0.1191 & -0.3024 & 0.1253 \\
\hline C16:1c9 (Palmitelaidic acid) & 0.6522 & 0.0002 & -0.2109 & 0.2911 & -0.2114 & 0.2897 \\
\hline C17:0 (Margaric acid) & 0.1186 & 0.5556 & 0.2461 & 0.2159 & 0.2517 & 0.2053 \\
\hline C17:1c10 (Heptadecenoic) & 0.5690 & 0.0020 & -0.1896 & 0.3435 & -0.1870 & 0.3503 \\
\hline C18:0 (Stearic acid) & -0.1058 & 0.5994 & 0.0253 & 0.9001 & 0.0273 & 0.8926 \\
\hline C18:1c9 (Oleic acid) & -0.0415 & 0.8370 & 0.2614 & 0.1879 & 0.2620 & 0.1867 \\
\hline C18:1c7 (Vaccenic acid) & $-0,0554$ & 0.7632 & 0.1345 & 0.2356 & 0.1643 & 0,3672 \\
\hline C18:2c9,12,16 (Linoleic acid) & -0.2590 & 0.1920 & -0.1425 & 0.4783 & -0.1455 & 0.4691 \\
\hline C20:0 (Arachidic acid) & 0.0453 & 0.8224 & 0.0691 & 0.7321 & 0.0741 & 0.7135 \\
\hline C20:1 (Eicosenoic) & $-0,0438$ & 0.8141 & 0.1290 & 0.3452 & 0.2645 & 0.3176 \\
\hline C18:3c9,12,15 ( $\alpha$-Linolenic acid $)$ & -0.0447 & 0.8249 & 0.1267 & 0.5290 & 0.1269 & 0.5283 \\
\hline C20:3c8,11,14 (Eicosatrienoic) & 0.2705 & 0.1723 & -0.0230 & 0.9093 & -0.0172 & 0.9320 \\
\hline C20:3c11,14,17 (Eicosatrienoic) & 0.3698 & 0.0576 & -0.2043 & 0.3066 & -0.1959 & 0.3275 \\
\hline C24:0 (Lignoceric acid) & -0.1651 & 0.4106 & -0.0583 & 0.7727 & -0.0671 & 0.7393 \\
\hline \multicolumn{7}{|l|}{ Fatty acid ratios $(\%)$} \\
\hline SFA (Saturated fatty acids) & 0.7230 & 0.001 & -0.3033 & 0.1241 & -0.2977 & 0.1315 \\
\hline MUFA (Monounsaturated fatty acids) & -0.0150 & 0.9409 & 0.2517 & 0.2053 & 0.2524 & 0.2041 \\
\hline PUFA (Polyunsaturated fatty acids) & -0.2512 & 0.2062 & -0.1450 & 0.4706 & -0.1477 & 0.4622 \\
\hline n-6 (Omega-6) & -0.2562 & 0.1970 & -0.1438 & 0.4743 & -0.1467 & 0.4653 \\
\hline n-3 (Omega-3) & 0.1962 & 0.3267 & -0.0220 & 0.9131 & -0.0165 & 0.9349 \\
\hline PUFA/SFA ratio & -0.7146 & 0.001 & 0.1709 & 0.3942 & 0.1658 & 0.4085 \\
\hline
\end{tabular}

induction time extrapolated to 25 and $30{ }^{\circ} \mathrm{C}$. This effect was observed for Algerian, which attained the lowest induction time extrapolated at both 25 and $30{ }^{\circ} \mathrm{C}$ but recorded the highest $\rho$-Anisidine value
(Table 4). This cultivar is more likely to experience secondary oxidation (oxidative rancidity) due to its level of unsaturation (PUFA), hence it will have a shorter shelf-life. 


\section{CONCLUSIONS}

The aim of the current study was to determine the oil content, fatty acid composition and physico-chemical quality parameters as well as the stability of cold-pressed seed oil from 12 commercially cultivated cultivars of cactus pear from the Bloemfontein, South Africa area. Large differences in oil content, fatty acid composition and physico-chemical properties (IV, PV, RI, tocopherols, ORAC, \% FFA, OSI and induction time) were observed. The quality parameters of the oils were strongly influenced by the oil content, fatty acid composition and physicochemical properties. Quality traits were mainly compared to previous studies on chemically extracted oils from South African cactus pear seed oil.

The main findings pointed out that cold-pressed oils yielded lower oil contents than chemically extracted oils, while green-colored fruit had the highest yields - indicating the effect of cultivar and species. The fatty acids showed similar profiles to those in chemically extracted oils, although the main fatty acid, linoleic acid (C18:2), content was lower. In general, lower PUFA and SFA contents and higher MUFA contents were observed than in the chemically extracted oils. RI, IV and $\rho$-AV was higher than observed in chemically extracted oils, while the PV, FFA and OSI were lower (shorter) - indicating good quality and stable oils. Tocopherol content and antioxidant activity contributed to stability and quality. Extrapolated induction times indicated a shelf-life of up to $\sim 3.5$ years when stored at $25^{\circ} \mathrm{C}$.

Overall, American Giant, Ofer, Van As, Zastron and Nudosa have proved to be the best performing cultivars in such a way that they contain the highest oil content, antioxidant capacity as well as greater stability to oxidation. Among all the cultivars, American Giant has showed to be the paramount cultivar with good quality traits (oil content and oxidative stability).

Future research should focus on the measurement of total flavonoids, total phenolics and sterols, specifically $\beta$-sitosterol, as well as the composition of volatile compounds of seed oils. These would all attribute to regional and varietal identities of the oils. Further perspectives include application of the oils in food products, as well as measuring its ability to function as antioxidants and anti-microbial agents.

\section{ACKNOWLEDGMENTS}

The authors wish to express their sincere gratitude to the following people and institutions: Dr. H.J. Fouche from the ARC for providing the fruit; $\mathrm{Mr}$. Fanie Rautenbach from CPUT for his assistance with the tocopherol and ORAC tests; the ARC-UFS-DUT collaborative consortium for funding of the project.

\section{REFERENCES}

Ali Alsaad AJ, Altemimi AB, Aziz SN, Lakhssassi N. 2019. Extraction and identification of cactus Opuntia dillenii seed oil and its added value for human health benefits. Pharmacog. J. 11 (3), 1-8. http://www.phcogj.com/v11/i3. https://doi. org/10.5530/pj.2019.3

AOAC. 2000. Oils and fats. In AOAC International Official Methods of Analysis, 17th Edition Association of Official Analytical Chemists, Gaithersburg.

Astiasarán I, Candela M. 2000. Edible fats. In: Astiasarán I. and Martínez JA (Eds) Food Composition and Properties, 2nd Ed. McGrawHill Interamericana, Madrid 109-133.

Boskou D. 2017. Edible cold pressed oils and their biologically active compounds. J. Exp. Food Chem. 3 (1), 1000e108. https://doi. org/10.4172/2472-0542.1000e108

Brahmi F, Haddad S, Bouamara K, Yalaoui-Guellal D, Prost-Camus E, Pais de Barros JP, Prost M, Atanasov AG, Madani K, BoulekbacheMakhlouf L, Lizard G. 2020. Comparison of chemical composition and biological activities of Algerian seed oils of Pistacia lentiscus L., Opuntia ficus-indica (L.) mill. and Argania spinosa L. skeels. Ind. Crops Prod. 151, 1-12. https://doi.org/10.1016/j.indcrop.2020.112456

Cao G, Sofic E, Prior R. 1996. Antioxidant capacity of tea and common vegetables. J. Agric. Food Chem. 44, 3426-3431. https://doi.org/10.1021/ jf9602535

Choe E, Min DB. 2006. Mechanisms and factors for edible oil oxidation. Comp. Rev. Food Sci. Tech. 5, 169-186. https://doi.org/10.1111/j.15414337.2006.00009.x

Chougui N, Tamendjari A, Hamidj W, Hallal S, Barras A, Richard T, Larbat R. 2013. Oil composition and characterization of phenolic compounds of Opuntia ficus-indica seeds. Food Chem. 193, 796-803. 
Chahdoura H, Barreira JCM, Barros L, SantosBuelga C, Ferreira ICFR, Achour L. 2015. Seeds of Opuntia spp. as a novel high potential byproduct: Phytochemical characterization and antioxidant activity. Ind. Crops Prod. 65, 383-389. https://doi.org/10.1016/j.indcrop.2014.11.011

Chu BS, Baharin BS, Quek SY. 2002. Factors affecting pre- concentration of tocopherols and tocotrienols from palm fatty acid distillate by lipase-catalysed hydrolysis. Food Chem. 79 (1), 55-59.

Ciriminna R, Bongiorno D, Scurria A, Danzi C, Timpanaro G, Delisi R, Avellone G, Pagliaro M. 2017. Sicilian Opuntia ficus-indica seed oil: fatty acid composition and bio-economical aspects. Eur. J. Lipid Sci. Tech. 119 (11). https://doi. org/10.1002/ejlt.201700232.

Codex Alimentarius Commission. 1999. Joint FAO/WHO Food Standards Programme. Codex committee on fats and oils. Rome.

Codex Alimentarius Commission. 2009. Codex standard for named vegetable oils- CODEX STAN 210-1999, Food and Agricultural Organization of the United Nation and the World Health Organization Codex Alimentarius Commission.

Ennouri MM, Evelyne B, Laurence M, Hamadi A. 2005. Fatty acid composition and rheological behavior of prickly pear seed oils. Food Chem. 93, 431-437. https://doi.org/10.1016/j.foodchem.2004.10.020

Fernández-Martínez JM, Velasco L, Pérez-Vich B. 2004. Progress in the genetic modification of sunflower oil quality. In: Proceedings of the 16th International Sunflower Conference, Fargo, ND, USA, 1-14.

Gharby S, Harhar H, Guillaume D, Haddad A, Matthäus B, Charrouf Z. 2011. Oxidative stability of edible argan oil: a two-year study. LWT - Food Sci. Tech. 44 (1), 1- 8. https://doi.org/10.1016/j. lwt.2010.07.003

Ghazi Z, Ramdani M, Fauconnier ML, El Mahi B, Cheikh R. 2013. Fatty acids sterols and vitamin E composition of seed oil of Opuntia ficus-indica and Opuntia dillenii from Marocco. J. Mater. Environ. Sci. 4 (6), 967-972. http://hdl.handle. net $/ 2268 / 156950$

Izquierdo NG, Aguirrezabal LAN, Andrade FH, Geroudet C, Valentinuzand O, Pereyra Iraola M. 2009. Intercepted solar radiation affects oil fatty acid composition in crop species. Field
Crop Res. 114, 66-74. https://doi.org/10.1016/j. fcr.2009.07.007

Hamilton RJ, Hamilton S. 1992. Lipid analysis: a practical approach. Oxford University Press.

Hssaini L, Hanine H, Charafi j, Razouk R, Elantari A, Ennahli S, Hernández F, Ouaabou R. 2020. First report on fatty acids composition, total phenolics and antioxidant activity in seeds oil of four fig cultivars (Ficus carica L.) grown in Marocco. Oilseeds and Fats, Crops and Lipids (OCL) 27 (8), 1-10. https://doi.org/10.1051/ ocl $/ 2020003$

Karabagias VK, Karabagias IK, Gatzias I, Badeka AV. 2020. Prickly pear seed oil by shelf-grown cactus fruits: waste or maste? Process 8, 132. https://doi.org/10.3390/pr8020132

Karleskind A, Wolff JP. 1996. Oils and fats manual: A comprehensive treatise - properties, production, application. A. Karleskind and J.-P. Wolff. (Eds.) 1527 pages. TEC and DOC Lavoisier, France, 1996. ISBN 1-898298-08-4. https://doi. org/10.1002/lipi.19970990608

Koshak AE, Abdallah HM, Esmat A, Rateb ME. 2020. Anti-inflammatory activity and chemical characterization of Opuntia ficus-indica seed oil cultivated in Saudi-Arabia. Arab. J. Sci. Eng. 1-8. https://doi.org/10.1007/s13369-020-04555-x

Kuti JO. 2004. Antioxidant compounds from four Opuntia cactus pear fruit varieties. Food Chem. 85, 527-533. https://doi.org/10.1016/S03088146(03)00184-5

Labuschagne MT, Hugo A. 2010. Oil content and fatty acid composition of cactus pear seed compared with cotton and grape seed. J. Food Biochem. 34, 93-100. https://doi.org/10.1111/ j.1745-4514.2009.00266.x

Lajara JR, Diaz U, Quidiello RD. 1990. Definite influence of location and climatic conditions on the fatty acid composition of sunflower seed oil. J. Am. Oil Chem. Soc. 67 (10), 618-623. https:// doi.org/10.1007/BF02540410

Loizzo MR, Bruno M, Balzano M, Giardinieri A, Pacetti D, Frega NG, Sicari V, Leporini M, Tundis R. 2019. Comparative chemical composition and bioactivity of Opuntia ficus-indica Sanguigna and Surfarina seed oils obtained by traditional and ultrasound-assisted extraction procedures Eur. J. Lipid Sci. Tech. 121, 1800283. https://doi. org/10.1002/ejlt.201800283 
Mannoubi I El, Barrek S, Skanji T, Casabianca H, Zarrouk H. 2009. Characterization of Opuntia ficus-indica seed oil from Tunisia. Chem. Nat. Comp. 45, 616-620. https://doi.org/10.1007/ s10600-009-9448-1

Márquez-Ruiz G, Martín-Polvillo M, Dobarganes MC. 1996. Quantitation of oxidised triglyceride monomers and dimers as a useful measurement for early and advanced stages of oxidation. Grasas Aceites 47, 48-53.

Martín-Polvillo M, Márquez-Ruiz G, Dobarganes MC. 2004. Oxidative stability of sunflower oils differing in unsaturation degree during longterm storage at room temperature. J. Am. Oil Chem. Soc. 81, 577-583. https://doi.org/10.1007/ s11746-006-0944-1

Martínez M, Barrionuevo G, Nepote V, Grosso N, Maestri D. 2011. Sensory characterization and oxidative stability of walnut oil. Int. J. Food Sci. Tech. 46, 1276-1281. https://doi.org/10.1111/ j.1365-2621.2011.02618.x

Morales P, Ramírez-Moreno E, Sanchez-Mata, MC, Carvalho AM, Ferreira, ICFR. 2012. Nutritional and antioxidant properties of pulp and seeds of two xoconostle cultivars (Opuntia joconostle F.A.C. Weber ex Diguet and Opuntia matudae Scheinvar) of high consumption in Mexico. Food Res. Int. 46, 279-285. https://doi.org/10.1016/j. foodres.2011.12.031

NazS, SheikhH,Siddiqi R, SayeedSA.2004. Oxidative stability of olive, corn and soybean oil under different conditions. Food Chem. 88, 253-259. https://doi.org/10.1016/j.foodchem.2004.01.042

Normand L, Eskin NAM, Przybylski R. 2006. Comparison of the frying stability of regular and high oleic acid sunflower oils. J. Am. Oil Chem. Soc. 83, 331-334. https://doi.org/10.1007/ s11746-006-1208-9

NCCS 11 Statistical Software NCSS Version 11.0.20, LLC. Kaysville, Utah, USA, 2018. ncss. com/software/ncss. Released 1 November 2018.

Ortega-Ortega MA, Cruz-Cansino SN, AlanísGarcía E, Delgado-Olivares L, Ariza-Ortega JA, Ramírez-Moreno E, de Jesús Manríquez-Torres J. 2017. Optimization of ultrasound extraction of cactus pear (Opuntia ficus-indica) seed oil based on antioxidant activity and evaluation of its antimicrobial activity. J. Food Qual. 2017, 1-9. https://doi.org/10.1155/2017/9315360
Pardo JE, Fernandez E, Rubio M, Alvarruiz A, Alonso GL. 2009. Characterization of grape seed oil from different grape varieties (Vitis vinifera). Eur. J. Lipid Sci. Tech. 111 (2), 188-193. https:// doi.org/10.1002/ejlt.200800052

Park, PW, Goins RE. 1994. In situ preparation of fatty acid methyl esters for analysis of fatty acid composition in foods. J. Food Sc. 59, 1262-1266.

Pearson JR. 1973. Alteration of dietary fatty acids by human intestinal bacteria. Proc. Nutri. Soc. 32, 8A-9A.

Prior RL, Hoang $\mathrm{H}, \mathrm{Gu} \mathrm{L}, \mathrm{Wu} \mathrm{X}$, Bacchiocca M, Howard L, Hampsch-Woodill M, Huang D, Ou B, Jacob R. 2003. Assays for hydrophilic and lipophilic antioxidant capacity (oxygen radical absorbance capacity (ORACFL)) of plasma and other biological and food samples. J. Agric. Food Chem. 51 (11), 3273-3279. https://doi. org/10.1021/jf0262256

Ramírez-Moreno E, Cariño-Cortés R, del Socorro Cruz-Cansino N, Delgado-Olivares L, ArizaOrtega LD, Montañez-Izquierdo VY, HernándezHerrero MM, Filardo-Kerstupp T. 2017. Antioxidant and antimicrobial properties of cactus pear (Opuntia) seed oils J. Food Qual. 1-8. https://doi.org/10.1155/2017/3075907

Rancimat Manual. 2009. Determination of the oxidative stability of the oils and fats. Metrohm AG, CH-9101, Herisau, Switzerland.

Regalado-Rentería E, Aguirre-Rivera JR, GonzálezChávez MM, Sánchez-Sánchez R, MartínezGutiérrez F, Juárez-Flores BI. 2018. Assessment of extraction methods and biological value of seed oil from eight variants of prickly pear fruit (Opuntia spp.). Waste Biomass. Valor. https://doi. org/10.1007/s12649-018-0409-4

Salvo F, Galati E, Lo Curto S, Tripodo M. 2002. Study on the chemical characterization of lipid composition of Opuntia ficus-indica L. seed oil. Acta Hort. 581, 283-289. https://doi. org/10.17660/ActaHortic.2002.581.33

Shahidi F, Zhong Y. 2005. Lipid oxidation: measurement methods. In: Bailey's industrial oil and fat products, 6th edition. John Wiley and Sons Incorporated, 357-385.

Sawaya WN, Khan P. 1982. Chemical characterization of prickly pear seed oil, Opuntia ficus-indica J. Food Sci. 47 (6), 2060-2061. https://doi. org/10.1111/j.1365-2621.1982.tb12946.x 
Tlili N, Bargougui A, Elfalleh W, Triki A, Nasri N. 2011. Phenolic compounds, protein, lipid content and fatty acids compositions of cactus seeds. $J$. Med. Plants Res. 5, 4519-4524.

Wit M de, Hugo A, Shongwe N. 2017. Quality assessment of seed oil from selected cactus pear cultivars (Opuntia ficus-indica and O. robusta). J. Food Proc. Pres. 41 (3), e12898 https://doi. org/10.1111/jfpp.12898
Wit M de, Hugo A, Shongwe N. 2018. South African cactus pear seed oil: a comprehensive study on 42 spineless Burbank Opuntia ficus-indica and Opuntia robusta cultivars. Eur. J. Lipid Sci. Tech. 120 (3), 1700343. https://doi.org/10.1002/ejlt.201700343 Zine S, Gharby S, ElHadekM. 2013.Physicochemical characterization of Opuntia ficus-indica seed oil from Morocco. Biosci. Biotech. Res. Asia 10 (1), 99-105. https://doi.org/10.13005/bbra/1099 